\title{
RESGATANDO O NEXO GOVERNANÇA- GESTÃO INTERNACIONAL: POR UMA NOVA ORDEM EM GESTÃO
}

\author{
Rescuing the international governance-management nexus: for a new order \\ in management
}

Rescatando el nexo gobierno-gestión internacional: por un nuevo orden en gestión

\section{RESUMO}

Este artigo vai além da literatura anglo-americana de gestão internacional (GI) e negócios internacionais (NI) e da ordem neoliberal ocidental correspondente, por meio de uma abordagem trans/interdisciplinar que resgata o nexo governança-gestão internacional. Com base nos fundamentos da transmodernidade pluriversal e no reconhecimento da dimensão de geopolítica que tem sido marginalizada por NI/GI, a análise do processo pós-199o de (re)construção de uma ordem luso-brasileira ou brasilo-portuguesa que desafia a hegemonia da ordem neoliberal é efetuada por meio do resgate da área de relações internacionais (RI) e da dessubalternização de conhecimentos locais baseados no conceito de diplomacia econômica. 0 artigo mostra como e por que organizações estatais e privadas mobilizam e constituem o nexo governança-gestão para (re)construir uma ordem luso-brasileira e ajudar a superar restrições históricas impostas pelo eurocentrismo. No final, o artigo defende a libertação de NI/GI para ajudar a construir uma nova ordem em gestão para um mundo em que diversos mundos e conhecimentos possam coexistir.

PALAVRAS-CHAVE | Governança, gestão internacional, negócios internacionais, geopolítica do conhecimento, Brasil-Portugal.

\section{ABSTRACT}

This article moves beyond international management (IM) and international business (IB) literatures and the corresponding neoliberal western order through a trans/interdisciplinary approach that rescues the international management-governance nexus. Drawing upon the basic tenets of pluriversaltransmodernity and the recognition of the geopolitical dimension that has been marginalized by IB/IM the analysis of post-199o process of (re)construction of a Luso-Brazilian or Brasilo-Portuguese order that challenges the hegemony of the neoliberal order is undertaken through the recognition of the international relations (IR) literature and the de-subalternization of local knowledges in GI/NI informed by the concept of economic diplomacy. This paper shows how and why business and government organizations mobilize and constitute the governance-management nexus to (re)build a Luso-Brazilian order and help overcome historical restrictions imposed by eurocentrism. In the end the article stands for the liberation of IB/IM as a way to build a new order in management towards a world in which many worlds and knowledges could coexist.

KEYWORDS I Governance, international management, international business, geopolítica do conhecimento, Portugal-Brazil.

\section{ANA LUCIA GUEDES}

almguedes@gmail.com Professora da Universidade do Grande Rio, Programa de PósGraduação em Administração - Rio de Janeiro - RJ, Brasil

\section{SERGIO WANDERLEY}

sergiow.gaz@terra.com.br Doutorando em Administração de Empresas pela Fundação Getulio Vargas, Escola Brasileira de Administração Pública e de Empresas - Rio de Janeiro - RJ, Brasil

\section{RESUMEN}

Este artículo va más allá de la literatura anglo-americana de gestión internacional (GI) y negocios internacionales (NI) y del orden neoliberal occidental correspondiente, por medio de un abordaje trans/interdisciplinario que rescata el nexo gobierno-gestión internacional. Con base en los fundamentos da transmodernidad pluriversal y en el reconocimiento de la dimensión de geopolítica que ha sido marginada por NI/GI, el análisis del proceso post 1990 de (re)construcción de un orden luso-brasileño o brasilo-portugues que desafía la hegemonía da orden neoliberal es efectuado por medio del rescate del área de relaciones internacionales (RI) y de la desubalternización de conocimientos locales basados en el concepto de diplomacia económica. El artículo muestra cómo y por qué organizaciones estatales y privadas movilizan y constituyen el nexo gobierno-gestión para (re)construir un orden luso-brasileño y ayudar a superar restricciones históricas impuestas por el eurocentrismo. A final, el artículo defiende la liberación de NI/GI para ayudar a construir un nuevo orden en gestión para un mundo en que diversos mundos y conocimientos puedan coexistir. PALABRAS CLAVE / Gobierno, gestión internacional, negocios internacionales, geopolítica del conocimiento, Brasil-Portugal. 


\section{INTRODUÇÃO}

A literatura euro-americana da grande área de NI/GI continua sendo tida como "universal" e "neutra", apesar de análises pós-colonialistas mostrarem o contrário (e.g. Westwood \& Jack, 2008). A literatura ajuda a tornar invisíveis as dimensões de geopolítica do conhecimento e de governança internacional que informam a hegemonia estadunidense e do eurocentrismo, e a restringir o reconhecimento e a construção de outras ordens e conhecimentos em um contexto marcado pela ascensão do neoimperialismo neoliberal e pelas seguidas crises da ordem ocidentalista (Mignolo, 2011; Steger, 2009). As principais teorias foram desenvolvidas no contexto da Guerra Fria, quando os EUA mobilizavam o complexo político-comercial-militar e marginalizavam o nexo governança-gestão para promover a ordem da pax americana por meio também do controle de instituições e áreas do conhecimento (Alcadipani, 2010; Jack, Calás, Nkomo, \& Peltonen, 2008). A grande área de $\mathrm{GI} / \mathrm{NI}$ foi mobilizada não apenas para deter o avanço do comunismo soviético, mas também para ajudar a construir e difundir instituições em negócios e gestão que servissem a essa ordem (Cooke, 2004). O projeto neoliberal de retomada da hegemonia estadunidense, iniciado nos anos 1970, vem permitindo que os EUA continuem impondo ao (Terceiro) mundo uma ordem ocidentalista (Mignolo, 2011) que privilegia a dimensão econômica e mantém invisível dimensões de (geo) política. Esse quadro restringe o reconhecimento e construção de outras ordens também no campo da gestão (Calás \& Smircich, 2013).

As assimetrias da globalização neoliberal liderada pelos EUA, a superpotência solitária no pós-Guerra Fria com incomparável poderio militar (Hurrell, 2006), foram consolidadas com a ascensão do unilateralismo estadunidense após os eventos de 11 de setembro de 2001 e a correspondente militarização da ordem neoliberal (Steger, 2009), que resultou na imposição de um regime de hegemonia forçada (Ikenberry, 2008), também chamado de neoimperialismo neoliberal (Duménil \& Lévy, 2011). A dimensão da geopolítica do conhecimento é um componente central na gestão dessa ordem ocidentalista (Mignolo, 2011; Miller, 2007; Nye, 2010). Isso ajuda a explicar por que a dimensão geopolíticade NI/GI continua sendo ignorada pela literatura euro-americana de $\mathrm{NI} / \mathrm{GI}$ e por que outras ordens e a ascensão de países emergentes ou semiperiféricos são tidas por instituições da governança ocidentalista como ameaçadoras para a ordem corrente (Hurrell, 2006; United Nations Conference on Trade and Development [Unctad], 2011).

Comparada à literatura de RI, a literatura de NI/GI ignora um amplo espectro de atores políticos e instituições do âmbito da governança internacional/global que é de central importância para o desempenho das grandes corporações (Strange,
1994), e também para que áreas do conhecimento ocidentalistas sejam tidas como "internacionais" (Hurrell, 2011). No contexto da Guerra Fria, a negação da área de RI pela área de NI/ GI e a manutenção da invisibilidade do complexo militar-industrial dos EUA e das dimensões de geopolítica do conhecimento podiam ser justificadas por muitos pelo temor mundial de uma guerra nuclear protagonizada pelo bipolarismo. No contexto atual, é injustificável manter a invisibilidade do nexo ocidentalista de governança-gestão; além de ser injusta, essa invisibilidade ajuda a bloquear a construção de um nexo de governança-gestão e áreas do conhecimento que sejam efetivamente "internacionais". Esse quadro restringe a construção de uma nova ordem em gestão que ajude a superar a crise da hegemonia do ocidentalismo e a construir um mundo em que diversos mundos e conhecimentos possam coexistir.

No pós-Guerra Fria, debates e deliberações sobre a área de $\mathrm{GI} / \mathrm{NI}$ continuam sendo dominados por instituições estadunidenses (e.g. Boddewyn,Toyne, \& Martínez, 2004; Martínez \& Toyne, 2000), de acordo com a universalidade epistêmica imposta há cinco séculos ao resto do mundo pela modernidade eurocêntrica. Ao resto do mundo, continua sendo negada a possibilidade de assumir responsabilidades em NI/GI e substituir a universalidade eurocêntrica e os processos subjacentes de violência, racismo e irracionalidade pela transmodernidade pluriversal (Dussel, 2011; Faria \& Guedes, 2010). Segundo a literaturade RI, os fluxos de investimento estrangeiro direto (IEDs) - que são analisados pela área de NI/GI sob uma perspectiva economicista e (neo) colonialista - estão relacionados a processos (geo) políticos de manutenção ou revisão da ordem ocidental liderada pelos EUA (e.g. Gilpin, 2001) e protagonizados pelo nexo de governança-gestão internacional e assimetrias correspondentes. Segundo essa literatura, negócios internacionais e gestão internacional são âmbitos de prática e de conhecimento informados por dimensões de (geo) política desprezadas pela literatura de GI/NI.

A literatura de NI/GI dissocia os âmbitos de gestão e governança e teoriza governança internacional como obstáculo exógeno quando se refere à gestão de grandes corporações no resto do mundo. Sob uma perspectiva ocidentalista, as dimensões de governança são teorizadas como anomalias ou patologias endêmicas de países menos desenvolvidos que obstruem a "boa gestão". A literatura de NI/GI usa a nomenclatura "business-government relations" (e.g. Grosse, 2005) para reforçar as ideias de que mercado e Estado são autônomos, de que o primeiro prevalece em relação ao segundo, e de que a ordem mundial é uma responsabilidade exclusiva do Ocidente. Em outras palavras, essa literatura torna visível e invisível o nexo governança-gestão internacional sob uma perspectiva ocidentalista que reforça as assimetrias entre Ocidente e resto do mundo, 
ou seja, a literatura torna visível o nexo governança-gestão para enfatizar o atraso endêmico do resto do mundo e mantém invisível o nexo governança-gestão suportado por uma superestrutura de governança global constituída por redes complexas envolvendo organizações privadas, governamentais, não governamentais e instituições internacionais ocidentalistas lideradas pelos EUA (McCrew, 2008). Em termos mais específicos, a literatura de NI/GI impõe, a pesquisadores e instituições do mundo inteiro, a ideia de que corporações do mundo euro-americano não fazem parte da gestão da governança global eurocêntrica (Alcadipani \& Caldas, 2012; Dar \& Cooke, 2008). Essas teorizações ocidentalistas, que ajudam a "gerenciar" o nexo governança-gestão sob uma perspectiva injusta e injustificável de geopolítica, marginalizam o resto do mundo em GI/NI e reforçam o grande quadro de colonialidade epistêmica que foi inaugurado quando a América foi "descoberta" pelos europeus (Ibarra-Colado, 2006). Esse projeto tornou-se uma das prioridades da governança ocidentalista no contexto pós-Guerra Fria, devido, principalmente, ao temor eurocêntrico de que outras ordens e teorizações "bárbaras" destruam a ordem civilizatória.

Este artigo desenvolve uma proposta trans/interdisciplinar "outra" a partir do contexto luso-brasileiro ou brasilo-português que torna visível o nexo governança-gestão sob uma perspectiva descolonizadora para ajudar a reconhecer e (re) construir outras ordens e conhecimentos em NI/GI. Esta proposta pretende ajudar a substituir o universalismo e a modernidade eurocêntrica pela pluriversalidade e transmodernidade.

Na próxima seção, desenvolvemos uma proposta trans/ interdisciplinar informada por debates na área de RI e pela transmodernidade pluriversal. Em seguida, promovemos a dessubalternização da literatura produzida por pesquisadores portugueses para resgatar o nexo gestão-governança por meio do conceito de diplomacia econômica. Apresentamos a metodologia na quarta seção, seguida da descrição e análise dos casos selecionados. Na última seção, abordamos como processos dedescolonização e libertação da área de GI/NI podem ajudar a construir uma nova ordem em gestão.

\section{UMA PERSPECTIVA TRANS/ INTERDISCIPLINAR NO (E A PARTIR DO) CONTEXTO LUSO-BRASILEIRO (OU BRASILO-PORTUGUÊS)}

Inaugurando um quadro de geopolítica do conhecimento marcado por violência, racismo e irracionalismo, o eurocentrismo representa uma conquista civilizatória baseada na imposi- ção da modernidade e do universalismo ao resto do mundo (e também à parte da própria Europa) ao longo dos últimos cinco séculos (Mignolo, 2011). Desde então, diferentes propostas de descolonização epistêmica têm sido promovidas e defendidas em diversos cantos do (resto do) mundo, em especial na América Latina (Escobar, 2004), para superar esse quadro da geopolítica do conhecimento. A opção descolonial que vem sendo desenvolvida nesta região propõe a substituição da modernidade eurocêntrica e do universalismo epistêmico correspondente pela transmodernidade pluriversal (Dussel, 2011). 0 objetivo central não é superar o eurocentrismo com “outro" eurocentrismo; tampouco é ignorar a modernidade em toda a sua extensão. Em termos práticos, a transmodernidade pluriversal defende a dessubalternização de conhecimentos "outros" e a reconstrução correspondente de epistemes que viabilizem a coconstrução de um mundo em que diversos mundos (e conhecimentos) possam coexistir.

Os problemas de colonização epistêmica impostos por esse quadro de geopolítica não vêm sendo enfrentados apenas por pesquisadores e instituições do Brasil -território que foi colonizado por Portugal e classificado pelo eurocentrismo como Terceiro Mundo no contexto da Guerra Fria e como economia emergente no pós-Guerra Fria - e de Portugal - o primeiro império colonial global que foi transformado pelo eurocentrismo em país semiperiférico e que protagonizou a mais longa experiência europeia de colonialismo. A manutenção desse quadro de geopolítica do conhecimento ao longo de séculos demandou que pesquisadores e instituições da Europa e dos EUA também fossem colonizados epistemicamente. Durante a Guerra Fria, a área de GI/NI tornou-se um recurso colonizador para viabilizar a ordem da pax americana. Muitos esperavam que a área se tornasse efetivamente "internacional" em décadas recentes, por causa da difusão da ideia de que o neoliberalismo representa uma ordem cosmopolita. Com a ascensão do unilateralismo neoliberal dos EUA após os eventos de 11 de setembro e os crescentes temores quanto à ascensão de países emergentes ou semiperiféricos, a área tornou-se um recurso estratégico para viabilizar a ordem neoimperial-neoliberal liderada pela superpotência e conter alternativas "ameaçadoras" (Hurrell, 2006). Em termos práticos, a proposta de transmodernidade pluriversal desenvolvida neste artigo é defendida como necessária para ajudar a fomentar diálogos entre periferias e, a partir daí, possibilitar um amplo diálogo assimétrico com o "centro", visto que o nexo governança-gestão continua geopoliticamente marginalizado em NI/GI, mesmo após a ascensão do unilateralismo dos EUA no início da década passada e o acirramento do (neo) ocidentalismo após a crise de 2008 (Ikenberry, 2008; Mignolo, 2011; Steger, 2009). 
Com a imposição da ordem neoliberal ocidental como ordem única e a institucionalização da tese de fim da história no início dos anos 1990 (Fukuyama, 1992), as ideias de que o privado é superior ao público e de que o Ocidente, liderado pelos EUA, é superior ao resto do mundo tornaram-se um dogma nos EUA (a chamada ilusão neoliberal). Esse dogma, co-construído e difundido por instituições acadêmicas e por um extenso aparato de geopolítica do conhecimento, ajudou a promover a súbita ascensão da área de NI/GI e a reforçar nos EUA o processo de colonização epistêmica iniciado com a Guerra Fria. Ajudou também a não apenas manter a marginalização geopolítica do nexo governança-gestão, mas também a suprimir conhecimentos "outros" produzidos no mundo euro-americano e "teorizações bárbaras" produzidas no resto do mundo. Na prática, esse grande processo (neo)colonial não suprimiu por completo outras ordens e movimentos de descolonização epistêmica. Em parte, o neoliberalismo catalisou o retorno (ou emergência) do resto do mundo - ilustrado pela ascensão da Índia, Rússia e China e também de outros países, como Brasil e África do Sul. No contexto luso-brasileiro ou brasilo-português, a literatura de RI negada pela grande área de NI/GI foi abraçada por organizações que constituem o nexo governança-gestão em Brasil e Portugal e também por pesquisadores locais dedicados a investigar o processo pós-199o de (re)construção de uma ordem que desafia a hegemonia da ordem neoliberal.

Colegas no mundo euro-americano ressaltam as limitações da área de NI/GI devidas ao seu caráter "etnocêntrico" ou “paroquial”(Cuervo-Cazurra, 2008; Ramamurti, 2009), para não reconhecerem o lado “colonialista”. Como desconhecedores das condições de possibilidade propostas pela transmodernidade pluriversal, e também como vítimas e beneficiários da ordem universalidade imposta pela modernidade eurocêntrica, eles não conseguem reconhecer outras ordens e conceber uma área "outra" que ajude a construir um mundo em que diversos mundos (e ordens) possam coexistir. Eles enfrentam um problema adicional: a negação da área de RI garante a invisibilidade do âmbito da geopolítica do conhecimento em NI/GI, apesar de tantas evidências contrárias (e.g. Faria, Ibarra-Colado, \& Guedes, 2010; Westwood \& Jack, 2008; Murphy \& Zhu, 2012).

Uma parte da literatura euro-americana de RI ressaltava, no início dos anos 1990, que a crescente interdependência gerada pelo fim da Guerra Fria exigia que governos desrespeitassem os discursos e as reformas que vinham impondo ao resto do mundo desde meados dos anos 1970. Enquanto uma corrente extrema de RI defendia o liberalismo e era mobilizada para os processos de imposição da ordem neoliberal, essa “outra” literatura euro-americana apontava que governos, corporações transnacionais e instituições internacionais - incluindo as chamadas "potências emergentes" - assumiriam papel central no âmbito da governança global (Stopford \& Strange, 1991). Diversos autores (Dicken, 1998; Gilpin, 2001; Grosse, 2005; Strange, 1994) anunciaram que o nexo governança-gestão internacional ficaria ainda mais importante do que havia sido durante a Guerra Fria. Essa literatura deveria ter provocado mudanças substantivas em $\mathrm{NI} / \mathrm{GI}$, especialmente no que diz respeito à teorização das interfaces entre organizações públicas e privadas (Haley, 2001) e ao âmbito da geopolítica do conhecimento (Miller, 2007).

Entretanto, assim como o neoliberalismo e seus dogmas transformaram-se em um grande pesadelo em escala global, a construção de uma nova perspectiva em NI/GI não foi possível. A esperada libertação de GI/NI em relação às restrições impostas pela Guerra Fria não poderia ocorrer, porque o neoliberalismo e tese de fim da história pressupunham o acirramento do eurocentrismo/ocidentalismo. Desde os primeiros momentos do pós-Guerra Fria, a ordem neoliberal ocidental afastou-se do multipolarismo neoliberal e aproximou-se cada vez mais do unilateralismo/unipolarismo - especialmente após os eventos de 11 de setembro e a substituição da Guerra Fria pela guerra global ao terror (Steger, 2009). As seguidas crises da ordem ocidental e a ascensão de países emergentes ou semiperiféricos tornaram ainda mais importantes as dimensões de geopolítica do sistema interestatal e de geopolítica do conhecimento. Esse quadro ajuda a explicar não somente as críticas pós-colonialistas em GI/NI como também a ascensão da opção descoIonial na América Latina e em outras periferias do mundo. Este artigo entende, então, que reconhecer a existência de outras ordens no mundo e colocar em prática a proposta de criar uma área de $\mathrm{NI} / \mathrm{GI}$ engajada com os fundamentos da transmodernidade pluriversal e enunciada em/por periferias do mundo pode ajudar a libertar o "centro" da área de GI/NI e, a partir daí, criar condições para uma nova ordem em gestão que ajude a construir um mundo em que diversos mundos e conhecimentos possam coexistir.

\section{RESGATANDO A DIPLOMACIA ECONÔMICA}

Colocar em prática a proposta de criar uma “outra” área de GI/ $\mathrm{NI}$ em (a partir) de contextos semi-periféricos ou emergentes é arriscado, mas necessário (Faria et al, 2010). Críticas ao caráter colonizador de GI/NI informadas pela teorização pós-colonialista têm sido enunciadas em países desenvolvidos, geralmente em língua inglesa. Ao privilegiar contextos específicos de colonização e desconsiderar as dimensões de geopolítica que a informa, essa teorização reproduz o universalismo eurocêntrico e 
marginaliza tanto a América Latina quanto processos intraeuropeus de colonização. Em termos mais práticos, essas importantes críticas desconsideram a possibilidade de que haja conhecimentos "outros" e práticas "outras", por desconhecerem as possibilidades advindas da transmodernidade pluriversal.

Logo após a deflagração da crise da ordem neoliberal ocidental de 2008, autores deste artigo iniciaram, então, um estágio acadêmico em Portugal para, entre outros objetivos, ajudar a tornar Brasil-Portugal (ou Portugal-Brasil) um locus de teorização em NI/GI que se movesse além da hegemonia estadunidense e do eurocentrismo. Por causa do quadro de geopolítica do conhecimento imposta pela modernidade eurocêntrica, o diálogo acadêmico entre Brasil e Portugal é escasso. Acadêmicos dos dois países estão conectados diretamente com EUA, Inglaterra e França, mas as conexões entre Brasil e Portugal são frágeis e desvalorizadas. 0 projeto baseava-se, então, no argumento de que o boom pós-199o de negócios envolvendo Brasil e Portugal representava um processo histórico de (re)construção de uma ordem que desafiava a hegemonia da ordem neoliberal ocidental liderada pelos EUA e permitia teorizações “outras” em GI/NI. Em vez de impor uma crítica universalista informada pela teorização pós-colonialista à literatura eurocêntrica de GI/NI produzida em Portugal, em cooperação com pesquisadores portugueses, o projeto concentrou-se em descobrir (e dessubalternizar) conhecimentos "outros" enunciados em Portugal, com base no reconhecimento da diferença colonial entre Portugal e o "centro" do eurocentrismo.

Abraçar conhecimentos "outros" produzidos por pesquisadores portugueses exigia coragem e cautela. Primeiro, devido ao temor de fortalecer cinco séculos de dominação; segundo, porque aquele conhecimento não seria útil para publicar nos principais outlets acadêmicos, nem mesmo no Brasil (ver Alves \& Aquino, 2011; Bertero, Alcadipani, Cabral, Faria, \& Rossoni, 2013). Críticas pós-colonialistas teriammais chances de publicação, especialmente se publicadas em inglês. Devido aos processos de ocidentalização mais extremos da área de $\mathrm{GI} / \mathrm{NI}$ a partir da ascensão do unilateralismo dos EUA, conhecimentos “outros” tendiam não apenas à marginalização, mas também à classificação de “bárbaros” pela ordem dominante.

A literatura focada no boom pós-1990 produzida no Brasil (Saraiva, 2000) era escassa, comparada à produção em Portugal (Barbosa, 2008; Carvalho, 2009; Costa, 2006; Leal, 2005; Silva, 2002a, 2002b, 2005, 2012). Em comum, a literatura nos dois países enfatizava as interfaces entre público e privado e, mais particularmente, entre governo e empresas. Na literatura portuguesa, foi, então, identificada a importância central do conceito de diplomacia econômica (Barbosa, 2008; Leal, 2005). Esse conhecimento "outro", baseado em literatura menos co- nhecida de RI e enunciado em país da Europa, torna visível o nexo gestão-governança sob uma perspectiva que desafia a hegemonia da ordem neoliberal. O estágio menos avançado de institucionalização de NI/GI em Portugal em relação ao Brasil permitia que pesquisadores portugueses usassem aquela literatura de RI.

O conceito de diplomacia internacional foi construído por monarquias europeias (do Norte) e teorizado por RI. Esse conceito, que nasceu logo após a inauguração do sistema internacional moderno/eurocêntrico em Westphalia, em 1648, forneceu um novo significado para práticas mercantilistas efetuadas por Espanha e Portugal nos séculos XV e XVI. A diplomacia tornou-se extremamente importante no século XIX para o imperialismo europeu, quando as recessões frequentes na região impeliram capitalistas locais a "usarem seus governos para garantir algum país subdesenvolvido distante por meio de anexação e proteção" (Hobson, 1965). No contexto da Guerra Fria, diferentes modalidades de diplomacia foram mobilizadas nas intervenções de redes complexas envolvendo negócios e geopolítica no Terceiro Mundo (Parmar, 2002). 0 mesmo pode ser dito quanto aos processos de colonização portuguesa na África e Ásia.

A despeito do poderio geoepistêmico dos discursos neoliberais que prescreveram o desmantelamento do Estado, as grandes potências reorganizaram-se geopoliticamente em torno do conceito de diplomacia econômica. Ministérios de relações exteriores e de comércio foram amalgamados e diferentes "estratégias de construção de ligações business-government dentro das instituições diplomáticas" foram implementadas (Lee \& Hudson, 2004, p. 343). Não surpreendentemente, a diplomacia econômica continuou sendo importante em/para Portugal.

Diplomacia econômica é um dos tipos de diplomacia, definido pelo eurocentrismo como “condução de relações entre estados e outras entidades com presença em política mundial por agentes oficiais e por meios pacíficos" (Bull, 1977, p. 156). Na prática, quando diplomacia econômica envolve relações entre as grandes potências e o resto do mundo, o eventual uso da força costuma ser descrito como recurso legítimo pela própria literatura de RI. Com o advento do neoliberalismo, diplomacia tornou-se um conceito menos vinculado a relações envolvendo apenas estados-nação, devido à crescente interdependência entre governos, corporações e organizações não governamentais. Ao supostamente eliminar a geopolítica e fortalecer a diplomacia econômica - incluindo países emergentes ou semiperiféricos que desafiavam a hegemonia da ordem neoliberal - o neoliberalismo promoveu a ascensão do nexo governança-gestão internacional.

O conceito de diplomacia econômica havia sido primeiramente negado por NI/GI no contexto da Guerra Fria, por cau- 
sa do papel exercido pelo complexo militar industrial dos EUA na gestão da ordem mundial (Parmar, 2002). A ativa participação de grandes corporações na política externa dos EUA e nas políticas de desenvolvimento e de ajuda internacional (Kunz, 1997), por meio da mobilização do nexo correspondente de governança-gestão, era característica central da diplomacia econômica na época (Bernstein \& Wilson, 2011). Naquele contexto, países colonizados também mobilizaram a diplomacia econômica, tanto em termos individuais quanto coletivos (vinculados ao terceiro-mundismo que emergiu após a Conferência de Bandung); por sua vez, essa diplomacia também viabilizou práticas neocoloniais no contexto do pós-colonialismo na África e Ásia, além de fomentar a construção das teorizações pós-colonialistas nos EUA (Dirlik, 2004).

No pós-Guerra Fria, a ascensão do unilateralismo dos EUA e a das economias emergentes marcaram a mobilização crescente da diplomacia econômica não somente por EUA e Europa mas também por países emergentes ou semiperiféricos (Nye, 2010). 0 êxito das estratégias de geopolítica da China na África e na América Latina no pós-Guerra Fria (Alves,2007), assim como a crescente importância das relações Sul-Sul e as novas responsabilidades assumidas pelo Brasil para construir a ordem mundial e "falar pelo Sul Global progressivo" (Hurrell, 2010, p. 6) ilustram a crescente importância da diplomacia econômica para o resto do mundo. Entretanto, com a vinculação da área de $\mathrm{NI} / \mathrm{GI}$ ao neoliberalismo, o conceito foi renegado, por ser vinculado ao Estado e à (geo)política, em vez de ao mercado e à economia. Esse quadro ajudou não apenas a tornar invisível em NI/GI a ascensão do unilateralismo dos EUA e o avanço do neoimperialismo neoliberal, mas também a elevar seu caráter eurocêntrico/ocidentalista.

Engajados com o conceito de diplomacia econômica e em grande medida desengajados da literatura de NI/GI e da hegemonia da ordem neoliberal subjacente, organizações privadas e estatais no Brasil perceberam que a adesão de Portugal à Comunidade Europeia em 1986 representava uma janela estratégica para garantir acesso ao mercado de Portugal e de outros países da União Europeia (Barbosa, 2008). O nexo de governança-gestão correspondente era importante também para a Comunidade Europeia em termos de gestão de geopolítica, devido ao lançamento do programa Guerra nas Estrelas pela administração Reagan. Organizações privadas e estatais de Portugal também perceberam que o Brasil, em particular, e a América Latina como um todo, eram geopoliticamente importantes para o país e para a Comunidade Europeia. Com o fim da Guerra Fria e a emergência de um mundo unipolar que parecia multipolar, a (re)construção de uma ordem luso-brasileira ou brasilo-portuguesa a partir do início dos anos 1990 tornou-se importante em termos geopolíticos para desafiar a hegemonia da ordem neoliberal ocidental liderada pelos EUA.

A literatura de RI focada nas relações Brasil-Portugal, em alusão aos 500 anos do “descobrimento", deu especial atenção ao processo de (re)construção de uma ordem que desafiava a hegemonia da ordem neoliberal liderada pelos EUA (Albuquerque \& Romão, 2000; Santos, Cohn, \& Camargo, 2001; Saraiva, 2000); porém, como a área de RI é negada por NI/GI, pesquisadores dos dois países não tiveram o direito epistêmico pleno de reconhecer esses "outros" (com menor intensidade em Portugal que no Brasil).

A literatura de $\mathrm{NI} / \mathrm{GI}$ continua teorizando o nexo governança-gestão como anomalia típica de países menos desenvolvidos, reforçando a teoria eurocêntrica de que corrupção no resto do mundo é endêmica. Segundo a literatura de NI, as estratégias de internacionalização de empresas são mais fáceis e menos arriscadas entre países desenvolvidos por causa da semelhança entre regimes institucionais e a correspondente superioridade (ver Dunning, 2006). Essa teorização ocidentalista mantém invisíveis não apenas a dimensão de geopolítica mas também as instituições de governança global - tais como a União Europeia, o Consenso de Washington, o Banco Mundial, a Organização Mundial do Comércio etc. - que exercem papel crucial para a construção e manutenção da hegemonia euro-americana nos âmbito de IED e comércio global. A proximidade cultural e linguística, traduzida como distância psíquica na literatura europeia (Johanson \& Vahlne, 1977), é, por sua vez, descrita pela área como uma dimensão que mitiga riscos e restrições causados por diferenças ou deficiências institucionais.

Curiosamente, pesquisas mostram que a proximidade cultural e linguística entre Brasil e Portugal não teve a esperada influência nos fluxos de IED (Silva, 2002a). A investigação sistemática do boom de IED pós-1990 mostrou que o fator mais importante continua sendo "o peso das relações diplomáticas no processo de internacionalização das empresas portuguesas no Brasil" (Silva, 2005, p. 109), ainda que empresas destaquem a proximidade cultural e linguística em suas estratégias de comunicação (ver Fernandes, Bandeira-de-Mello, \& Zanni, 2012). Pesquisadores portugueses argumentam que são necessários "novos quadros teóricos que forneçam uma melhor articulação entre a dimensão econômica e a dimensão cultural" (Costa, 2006, p. 46). Entretanto, pesquisadores e instituições portuguesas não têm voz elevada na área de NI/GI, devido a questões de geopolítica que são negadas pela literatura. Este artigo argumenta, então, que o resgate do nexo governança-gestão e o engajamento com a teorização marginal mobilizada por pesquisadores portugueses são importantes para descolonizar e libertar NI/GI e ajudar a substituir a universalidade 
epistêmica imposta pela modernidade eurocêntrica pela transmodernidade pluriversal.

\section{METODOLOGIA}

A pesquisa empírica investigou a importância do nexo governança-gestão nos fluxos de IED de empresas portuguesas no Brasil e de empresas brasileiras em Portugal no período de 1996 a 2011. Cabe destacar que, desde a adesão de Portugal à União Europeia, em 1986, o aparato regulatório tem sido estável e não discriminatório para fomento e atração de IED (Simões \& Cartaxo, 2011). Portugal criou, ao contrário do Brasil, uma Agência para o Investimento e Comércio Externo de Portugal (Aicep), responsável por promover tais investimentos.

Foram selecionadas fontes oficiais de dados referentes aos fluxos de IED com destino em Portugal e Brasil, de acordo com procedimentos seguidos pela literatura de economia política internacional em NI (Grosse, 2005; Grosse \& Behrman, 1992; Stopford, 2005; Strange, 1994) e pesquisas conduzidas em Portugal (Rosa, 2011; Silva, 2002a, 2005, 2006; Simões \& Cartaxo, 2011). Para contornar algumas discrepâncias entre fontes dos dois países, foram coletados e filtrados dados de diversas fontes e origens: Banco Central do Brasil (www.bacen.gov.br), United Nations Conference on Trade and Development (www. unctad. org), Organization for Economic Co-operationand Development (www.oecd.org), Agência para o Investimento e Comércio Externo de Portugal (www.aicep.pt), Banco de Portugal (www.bportugal.pt).

A análise dos fluxos de IED de Portugal para o Brasil mostrou que, partindo de valores incipientes até então, houve, no período 1998-2001, um total de investimentos líquidos de USD 9,63 bilhões (Aicep, 2012). Esse período coincide com o momento principal das privatizações no Brasil do setor de serviços, com os primeiros momentos da diplomacia econômica portuguesa pós-1990 e com os primeiros sinais da obsolescência neoliberal. No período de 1996 a 2005, o Brasil investiu em Portugal um total bruto de USD 1,67 bilhões (Aicep, 2012). Segundo dados fornecidos pelo Dossier Mercado Brasil (Aicep, 2012), os fluxos entre os países intensificaram-se após a crise de 2008: Portugal mantém o Brasil na quarta posição como destino de IED, enquanto o Brasil passa da $14^{\mathrm{a}}$ para a sétima posição de investidor estrangeiro em Portugal.

Adicionalmente, foram coletados dados referentes à composição acionária de todas as empresas identificadas como de origem no Brasil com investimentos em Portugal e vice-versa. Dois estudos de casos foram, então, selecionados-tratados como estudo de casos múltiplos (Eisenhardt \& Graebner,
2007; Stake, 2005) - protagonizados por empresas que tinham participações acionárias cruzadas. Esses estudos mostram, de modo mais abrangente, a importância do nexo governança-gestão internacional sob a perspectiva trans/interdisciplinar desenvolvida neste artigo.

\section{DESCRIÇÃO E ANÁLISE DOS CASOS}

Os casos múltiplos descritos a seguir mostram como e por que o nexo governança-gestão, envolvendo relações governo-empresa e empresa-empresa, é importante para o boom pós-1990. Destaca-se o surpreendente resultado de participações acionárias cruzadas e a presença de agentes "outros", tais como os fundos de pensão, fundos private equity e fundos soberanos. Após o agrupamento de todas as empresas brasileiras e portuguesas com investimentos nos dois países, foram identificadas aquelas em que a presença do Estado, por via direta ou indireta, teve ou ainda tem papel mais destacado na governança e gestão dos processos de internacionalização correspondentes (ver Quadro 1).

\section{QUADRO 1. Empresas selecionadas - casos múltiplos}

\begin{tabular}{l|l|l}
\hline Casos & $\begin{array}{l}\text { Empresas } \\
\text { brasileiras }\end{array}$ & Empresas portuguesas \\
\hline $\begin{array}{l}\text { Caso 1: } \\
\text { Concessão de } \\
\text { serviços públicos }\end{array}$ & Oi & $\begin{array}{l}\text { Portugal Telecom } \\
\text { EDP (b) }\end{array}$ \\
\hline $\begin{array}{l}\text { Caso 2: } \\
\text { Aeronaves, } \\
\begin{array}{l}\text { aviação e defesa } \\
\text { (a) }\end{array}\end{array}$ & Embraer & $\begin{array}{l}\text { EMPORDEF } \\
\text { OGMA }\end{array}$ \\
\hline
\end{tabular}

Notas: (a) Consideramos na análise a EADS, empresa europeia com atividades em Portugal, por meio da Helibras no Brasil. (b) EDP atua no Brasil.

\section{Caso 1 - Setor de concessão de serviços públicos}

No âmbito de concessão de serviços públicos, a diplomacia econômica teve papel central no processo correspondente de (re)construção de uma ordem luso-brasileira por meio de incentivos diretos a investimentos portugueses no Brasil. Pesquisas em Portugal destacam o papel da diplomacia econômica durante a gestão do Primeiro-Ministro Antonio Guterres, de 1996 a 2001 (e.g. Leal, 2005). Antonio Guterres inaugurou uma nova visão nas relações entre os países ao propor uma aliança econômica no pós-1990 que era mais (geo)política do que econômica propriamente dita. Na primeira visita oficial bilateral ao Brasil, 
em abril de 1996, o primeiro-ministro foi acompanhado de ampla comitiva de empresários e gestores de vários setores (envolvendo organizações públicas e privadas). Essa visita oficial teve grande importância, por impactar profundamente não apenas as relações bilaterais mas também as políticas internacionais de ambos os países em seus espaços regionais respectivos - Mercosul e União Europeia - diante dos excessos e equívocos da ordem neoliberal liderada pelos EUA. Ainda em 1996, foi assinado o acordo que criou a Comunidade dos Países de Língua Portuguesa (CPLP), reforçando o âmbito geoepistêmico daquela política de diplomacia econômica dos dois países e também de outros países que constituem o mundo lusófono perante o avanço neoliberal do imperialismo da língua inglesa. A criação da CPLP coincidia com a ascensão da diplomacia asiática e os primeiros sinais mais óbvios de fracasso do neoliberalismo. Esse acordo era particularmente interessante sob uma perspectiva de geopolítica porque tinha uma ex-colônia (no caso, o Brasil) como principal fomentador (Fontoura, 2007).

Com a deflagração da Crise Asiática em 1997 e o acelerado declínio da ordem neoliberal ocidental e do Consenso de Washington, aquela política de diplomacia econômica iniciada por Guterres foi consolidada naquele mesmo ano pela Resolução 61 do Conselho de Ministros. Esta declarou a opção de Portugal ter o Brasil como parceiro preferencial na internacionalização de empresas portuguesas. Foram, então, criados outros instrumentos voluntários de diplomacia econômica: realização de encontros anuais, celebração de acordos gerais para impulsionar o IED e construção de facilitadores para a entrada das organizações portuguesas nas privatizações no Brasil (Barbosa, 2008). Além disso, foi iniciada, em Portugal, a Nova Política para a Internacionalização como o primeiro enquadramento legal dessa política. Várias parcerias empresariais foram estabelecidas para fortalecer os investimentos portugueses nas privatizações do Brasil, com especial destaque para os setores de telecomunicações, bancário e turismo. Visto que não havia um grande acordo geral formal de integração econômica entre os dois países, esse acabou se tornando o mais importante caso de aplicação da diplomacia econômica portuguesa (Leal, 2005).

Com o programa de privatizações estabelecido pelo Governo Fernando Henrique Cardoso (1992-2000), a Portugal Telecom (PT) e a Energias de Portugal (EDP) efetuaram importantes aquisições no Brasil no âmbito de concessão de serviços públicos. Esses investimentos cristalizaram os esforços da política de diplomacia em setores que eram mais sensíveis em termos de geopolítica (Barbosa, 2008). A PT, cuja privatização em Portugal foi iniciada em 1995, adquiriu participação minoritária em 1998 no consórcio vencedor da Telesp Celular, que posteriormente se chamaria Vivo e se tornaria a maior operadora móvel da América Latina e a quarta em nível mundial. Essa aquisição, de USD 4 bilhões, representou, na época, a segunda maior privatização no mundo e o pico do volume de IED de Portugal no Brasil (Silva, 2005). Num longo episódio que só terminou no início de 2011 e que teve a intervenção da Comunidade Europeia, a PT desfez-se de sua participação na Vivo para posteriormente adquirir uma participação de $22,4 \%$ na Oi, em uma troca de participações com a Telefonica (empresa espanhola), que teve a aprovação do governo brasileiro de acordo coma estratégia do governo de Lula da Silva de constituir uma gigante de telecomunicações nacional, que se transformou em lusófona, capaz de desafiar a ordem econômico-político-linguística de um setor que ficou particularmente importante em termos de geopolítica após os eventos de 11 de setembro (Porto-Gonçalves, 2008).

A dimensão de geopolítica e o nexo correspondente de governança-gestão também tiveram destaque no processo de entrada da EDP no Brasil (Fernandes et al, 2012).Tanto a estrutura acionária da PT (Grupo Espiríto Santo - 10\%; RS Holding 10\%; Telemar Norte Leste - 7\%; Caixa Geral de Depósitos - 6\%; Norges Bank - $5 \%$; Capital Research Management - $5 \%$; UBS AG - 5\%; Brandes Investments Partners - 4\%; Europacific Growth Fund - 3\%; Grupo Visabeira - 3\%; Barclays Plc - 3\%; Black Rock Inc. - $2 \%$ e Controlinvest e International Finance - $2 \%$, PORTUGAL TELECOM, 2012) quanto a estrutura da EDP (Parpública 25\%; Iberdrola Energia - $7 \%$; Liberbank - $5 \%$; José de Mello S.A. - $5 \%$; Senfora SARL - 4\%; Grupo BCP e fundos de pensões do BCP - 3\%; Sonatrach - 2\%, Banco Espírito Santo - 2\%; Qatar Holding - 2\%; Caixa Geral de Depósitos e EDP - 1\% cada; EDP, 2012) incluem empresas privadas de capital aberto fortemente conectadas a organizações governamentais dos dois países.

Além de organizações privadas e públicas dos dois países, merece destaque a presença de outros atores e instituições na estrutura de governança dessas duas empresas: (a) fundos de pensão na EDP; (b) fundos de private equity na PT; (c) fundos soberanos da Noruega na PT e (d) fundos do Qatar na EDP. A dimensão geopolítica ampliada do nexo governança-gestão nesses dois casos ainda não foi explorada por pesquisadores portugueses, devido à ênfase à diplomacia econômica portuguesa sob uma perspectiva nacionalista, em detrimento de uma perspectiva descolonizadora de RI que se tornou necessária para a teorização não eurocêntrica da governança global (ver Hurrell, 2011). Em dezembro de 2011, a companhia estatal chinesa China Three Gorges adquiriu da Parpública 21,35\% do capital social da EDP, especialmente devido não somente aos avanços da ordem chinesa na África e na América Latina e aos investimentos de Portugal e Brasil na África e na China, que ampliam o processo de (re)construção de uma ordem luso-brasileira ou brasilo-portuguesa, mas também aos movimentos ocidentalistas 
liderados pelos EUA para conter ou "gerenciar" os tentativas de fortalecimentos de "outras" ordens (Ikenberry, 2008).

É importante destacar que nesses setores investigados - i.e, telecomunicações e energia - a importância da dimensão geopolítica e do nexo de governança-gestão internacional ficou mais saliente com a ascensão do unilateralismo dos EUA e a crescente relevância das grandes economias emergentes no âmbito da governança global (Porto-Gonçalves, 2008).

\section{Caso 2 - Indústrias de aeronaves, aviação e defesa}

Esse é um setor em que questões de segurança nacional e de geopolítica são tão ou mais importantes do que no caso anterior. A participação do Estado no nexo de governança-gestão manifesta-se obrigatoriamente, apesar de a literatura de NI/GI manter invisível a dimensão geopolítica correspondente, mesmo após os eventos de 11 de setembro e a ascensão do unilateralismo dos EUA. Análise histórica da composição acionária de empresas nesse setor mostra a importância de uma estrutura de governança mais estado-cêntrica (governo-empresa-governo), uma variedade do nexo governança-gestão que costuma ser associada à corrupção pela literatura de GI/NI.

Merece destaque neste caso a Empresa Brasileira de Aeronáutica [Embraer] (2011), que vem sendo celebrada pela literatura de $\mathrm{NI}$ como exemplo de internacionalização de empresa privada realizada em país menos desenvolvido (Casanova, 2009). Essa literatura esquece - ou torna invisível, para manter a invisibilidade dos diferentes arranjos liderados pelo campo da defesa nacional no mundo euro-americano - que a Embraer foi criada em 1969 pelo governo brasileiro em período delicado da Guerra Fria. Por meio de uma política de reserva de mercado ao longo de duas décadas e de políticas industriais baseadas em teorizações “bárbaras” negadas por GI/NI (em especial a teoria da dependência) que desafiavam as políticas de desenvolvimento internacional impostas pelos EUA ao Terceiro Mundo no contexto da Guerra Fria, a empresa atingiu patamares de excelência até ser privatizada em 1994. A literatura celebratória de NI ignora o argumento de que a trajetória da Embraer exige que especialistas em desenvolvimento internacional "reconsiderem a premissa de que o protecionismo gera inevitavelmente empresas sem competitividade" (Wells, 2009, p. 12).

A Embraer é uma empresa de capital aberto com ações cotadas na bolsa de São Paulo e ADRs na bolsa de Nova lorque. Entretanto, a governança da empresa é complexa por causa do nexo governança-gestão e de questões de diplomacia econômica que se misturam com geopolítica. Tendo em vista a importância estratégica dessa organização para o complexo de defesa do País, o governo brasileiro manteve uma goldenshare por meio da qual pode evitar que acionistas privados consigam atingir a maioria do capital, seja individualmente ou em grupo (desenho parecido com o da PT em Portugal). Ademais, não há um bloco bem definido de controle acionário; a maioria dos membros do conselho de administração é independente, ou seja, não ligada a nenhum dos acionistas.

Análise cuidadosa de sua composição acionária revela a presença do governo brasileiro, fundos de pensão e fundos de private equity (Previ - 11\%; Oppenheimer Funds- 8\%; Thornburg Investment Management - 7\%; BNDESPar- 5\%; Black Rock Inc. - 5\% e Cia Bozano - 4\%; BMF BOVESPA, 2012). Em dezembro de 2004, associada à European Aeronautic Defence and Space Company (EADS), a empresa venceu o leilão de privatização da OGMA (Indústria Aeronáutica de Portugal S.A.). A OGMA, com sede em Alverca, é uma empresa portuguesa qualificada no setor da aviação civil e militar que se dedica à manutenção, reparação e revisão geral de aeronaves, motores e acessórios (Embraer, 2011). A EADS, por sua vez, é uma empresa do setor aéreo e de defesa que congrega a participação acionária de governos europeus. 0 governo português, por meio da holding Empordef, manteve uma participação minoritária de 30\% na OGMA; os outros 70\% estão com Embraer (70\%) e EADS (30\%). A Empordef consolida a participação acionária do governo em empresas da área de defesa e é responsável pela definição de estratégias de defesa do Ministério da Defesa Nacional. Após a Embraer vencer o leilão de licitação da OGMA, em 2005, em uma potencial demonstração de reciprocidade, a TAP, que pertence $100 \%$ ao governo português, por meio da Parpública S.A., venceu a licitação para assumir a área de manutenção de aeronaves da antiga Varig no Brasil, que era controlada pelo governo brasileiro.

Em 2008, a Embraer iniciou investimentos em Évora para a produção de partes para aeronaves. Esses investimentos estão alinhados com a estratégia do governo português de formação de clusters de indústrias voltadas para a defesa (Embraer, 2011). Ao se associar à Empordef, por meio do controle da OGMA, a Embraer passou a seguir a estratégia ditada pela última, apesar de a Empordef ter um controle minoritário na OGMA. Essa análise desafia a literatura ocidentalista que descreve essa organização como modelo de empresa moldada pela ordem neoliberal. Este estudo revela uma intrincada teia de organizações com participações cruzadas de diferentes governos - englobando Brasil, Portugal, outros países da Europa e outros países emergentes ou semiperiféricos - que não foi explorada por pesquisadores portugueses. Análise mostra que o resgate do nexo governança-gestão por meio de uma teorização informada pela transmodernidade pluriversal e enunciada em "periferias" demanda a descolonização do conceito de diplomacia econômica. 
A análise dos casos revela a presença de agentes outros representando capital privado em fundos de private equity (casos 1 e 2), capital público como fundos soberanos (caso 1) e capital híbrido em fundos de pensão (casos 1 e 2). Esse desenho de governança, que vem sendo negligenciado pela literatura dominante (como exceção, ver Ramamurti, 2011), confirma a importância do resgate do nexo governança-gestão internacional por pesquisadores e instituições nas periferias. Diálogos críticos entre periferias também são necessários, assim como o estabelecimento de um diálogo coletivo com o "centro" para ajudar a libertar a área de GI/NI.

\section{CONSIDERAÇÕES FINAIS}

Este artigo mostrou a importância de resgatar o nexo governança-gestão internacional em $\mathrm{Gl} / \mathrm{NI}$ por meio de uma perspectiva enunciada no (e a partir do) contexto brasilo-português (ou luso-brasileiro) que desafia o caráter ocidentalista da área e torna visíveis dimensões de geopolítica. Ao desafiar o quadro de marginalização geopolítica produzida pela área de GI/NI, esse nexo não foi teorizado neste artigo como um segredo necessário para a manutenção da ordem ocidentalista ou como patologia ou anomalia típica do resto do mundo. A construção de uma "outra" área de NI/GI que vá além da hegemonia euro-americana demanda, então, o resgate de outros loci de teorização e enunciação.

Os casos investigados confirmam a importância de resgatar o nexo governança-gestão internacional por meio do reconhecimento da literatura de RI e do conceito de diplomacia econômica. A proposta desenvolvida neste artigo vai além dos avanços produzidos por pesquisadores portugueses, por mostrar a necessidade de uma reteorização descolonizadora do conceito de diplomacia econômica. Influenciados pelo caráter eurocêntrico de RI e pelos processos de colonização protagonizados por Portugal, pesquisadores portugueses têm privilegiado o conceito de diplomacia econômica sob uma perspectiva nacionalista que impede o reconhecimento dos múltiplos contextos de diplomacia econômica mobilizados por diferentes nexos de governança-gestão nas diversas "periferias" que constituem ordens que desafiam a hegemonia da ordem neoliberal ocidental.

Ao ir além da perspectiva ocidentalista da área de GI/ $\mathrm{NI}$ e também da perspectiva nacionalista que informa a pesquisa portuguesa baseada no conceito de diplomacia econômica, o artigo mostrou, então, que o nexo governança-gestão é de central importância para o reconhecimento não apenas do processo de (re)construção de uma ordem luso-brasileira ou brasilo-portuguesa, a partir do boom pós-1990, mas também de outras ordens em diversas outras periferias que constituem um mundo em que diversos mundos e ordens coexistem. Os autores esperam que este artigo encoraje instituições e pesquisadores de "periferias" em geral, e no contexto luso-brasileiro em particular, a fomentar investigações e teorizações descolonizadoras focadas no nexo governança-gestão e no conceito de diplomacia econômica para a coconstrução de uma "outra” área de GI/NI.

As seguidas crises da ordem neoliberal ocidental e os crescentes temores eurocêntricos de que "outras" ordens venham a destruir a ordem civilizatória que vem sendo imposta há cinco séculos têm acirrado o quadro de colonialidade epistêmica na área de NI/GI, não apenas nas periferias mas especialmente no "centro". A efetiva descolonização de GI/NI demanda a constituição de diálogos críticos entre conhecimentos enunciados na "periferia" e entre estes e o "centro" da área. Por meio da mobilização do nexo governança-gestão que informa a geopolítica do conhecimento da área, a libertação de pesquisadores e instituições acadêmicas de GI/NI do "centro" é de vital importância para a construção de uma nova ordem em gestão que leve a um mundo em que diversos mundos e conhecimentos possam coexistir.

Este artigo sugere, então, que Brasil e Portugal devem e podem assumir responsabilidades, especialmente por meio do engajamento com a CPLP, para fomentar a substituição do universalismo epistêmico estabelecido pela modernidade eurocêntrica em GI/NI pela transmodernidade pluriversal vinda das periferias. Conforme afirma o ex-presidente de Portugal Mario Soares:

Felizmente, não dependemos hoje exclusivamente da União Europeia. Digo-o e sou, como sabem, um europeísta convicto, embora muito apreensivo quanto ao seu futuro. Pertencemos à CPLP e à Ibero-América e temos uma posição destacada e verdadeiramente estratégica no Atlântico, que não devemos subestimar. Não o esqueçamos nunca (Diário de Notícias, 2010, p.1).

Argumentamos, então, que pesquisadores, organizações e instituições nesses dois países devem reconhecer que a mobilização, na prática, do nexo de governança-gestão sob uma perspectiva descolonizadora de RI (i.e, que vá além de nacionalismos ou regionalismos) é condição necessária para viabilizar esse desafiante processo de descolonização e libertação da área de GI/NI. 


\section{REFERÊNCIAS}

Agência para o Investimento e Comércio Externo de Portugal. (2012). Recuperado em 24 março, 2012, de http://www.ciep.pt/public/files/ brasildossiermercado.pdf.

Albuquerque, R, \& Romão, A. (2000). Brasil - Portugal: desenvolvimento e cooperação: o diálogo dos 500 anos. Rio de Janeiro: EMC.

Alcadipani, R. (2010). From Latin America to the world: notes on the (possible) Latin American management styles. In A. Guedes, \& A. Faria (Eds.). International management and international relations. London: Routledge.

Alcadipani, R, \& Caldas, M. (2012). Americanizing Brazilian management. Critical Perspectives on International Business, 8(1), 37-55.

Alves, D.(2007). A presença chinesa em África: o caso de Angola. Negócios Estrangeiros, 10, 56-71.

Barbosa, A. T. (2008). Relações luso-brasileiras: passado, presente e futuro [Working Papers, Linha de investigação: Europa, Segurança e Migrações]. Centro de Estudos da População, Economia e Sociedade. Recuperado em 25 abril, 2012, dehttp://www.cepese.pt/portal/ investigacao/working-papers/relacoes-externas-de-portugal/relacoesluso-brasileiras-passado-presente-e-futuro/Relacoes-luso-brasileiraspassado-presente-e.pdf.

Bernstein, M, \& Wilson, M. (2011). New perspectives on the history of the military-industrial complex. Enterprise and Society, 12(1), 1-9.

Bertero, C, Alcadipani, R, Cabral, S, Faria, A, \& Rossoni, L. (2013). Os desafios da produção de conhecimento em administração no Brasil. Cadernos EBAPE.BR, 11(1), 181-196.

Boddewyn, J, Toyne, B, \& Martínez, Z. L. (2004). The meanings of 'international management'. Management International Review, 44(2), 195212.

Bull, H. (1977). The anarchical society. London: McMillan.

Calás, M, \& Smircich, L. (2013). Organization@21 The journal of disconcerting organization theory and action. Organization, 20(1),13-24.

Carvalho, T. (2009). O investimento português no Brasil e os desafios futuros. Tese de doutorado, Ciência Política, Universidade Lusófona de Humanidades e Tecnologias, Lisboa.

Casanova, L. (2009). Global Latinas. Hampshire: Palgrave MacMillan.

Cooke, B. (2004). The managing of the (Third) World. Organization, 11(5), 603-629.

Costa, C. (2006). Proximidade cultural e dinamismo econômico: por que investem as empresas portuguesas do Brasil. RAE-Revista de Administração de Empresas, 46(Edição Especial), 35-47.

Cuervo-Cazurra, A. (2008). The multinationalization of developing country MNEs: the case of multilatinas. Journal of International Management, 14(2), 138-154.

Dar, S, \& Cooke, B. (2008). The new development management: critiquing the dual modernization. London: Zed Books.

Diário de Notícias. (2010). Opinião. A Europa e a crise, por Mario Soares, 1-4. Recuperado em 29 junho, 2013, de http://www.dn.pt/ inicio/opiniao/interior.aspx?content_id $=1489957$.

Dicken, P. (1998). Global shift - transforming the world economy (за ed.). London: Paul Chapman.
Dirlik, A. (2004). Spectres of the Third World. London: Routledge.

Duménil, G, \& Lévy, D. (2011). The crisis of neoliberalism. Cambridge: Harvard University.

Dunning, J. (2006). Towards a new paradigm of development: implications for the determinants of international business. TransnationalCorporations, 15(1), 173-227.

Dussel, E. (2011). Transmodernidad e interculturalidad (interpretacion desde la filosofia de la liberacion). In E. Lander (Org.). La colonialidad del saber: eurocentrismo y ciências sociales(2a ed.). Buenos Aires: Clacso.

Eisenhardt, K, \& Graebner, M. (2007). Theory building from cases: opportunities and challenges. Academy of Management Journal, 50(1), $25-32$.

Empresa Brasileira de Aeronáutica. (2011). Informações Divulgadas ao Mercado. Relatórios Anuais. Relatório Anual 2011. Recuperado em 8 setembro, 2011, de ttp://ri.embraer.com.br/show.aspx?idCanal=iM2P2p1lloUsWi5mzDbdbA==.

Energias de Portugal (2012). Investidores. Publicações. Recuperado em setembro, 2013 de http://www.edp.pt/pt/investidores/accaoedp/ estruturaaccionista/Pages/ShareholderStructure2.aspx.

Escobar, A. (2004). Beyond the Third Word: imperial globality, global coloniality and anti-globalization social movements. Third World Quarterly, 25(1), 207-230.

Faria, A, \& Guedes, A. (2010). What is international management? In A. Faria, \& A. Guedes (Eds.). International Management and International Relations (pp. 1-26). London: Routledge.

Faria, A, Ibarra-Colado, E, \& Guedes, A. (2010). Internationalization of management, neoliberalism and the Latin America challenge. Critical Perspectives on International Business, 6(2/3), 97-115

Fernandes, C, Bandeira-de-Mello, R, \& Zanni, P. (2012). O papel dos fatores políticos na internacionalização de empresas: o caso da Energias de Portugal (EDP) no Brasil. Cadernos EBAPE.BR, 10(2), 435-455.

Fontoura, L. (2007). CPLP: a importância do Brasil no espaço lusófono. Negócios Estrangeiros, 11(1), 350-372.

Fukuyama, F. (1992). The end history and the last man. New York: Free Press.

Gilpin, R. (2001). Global political economy. Princeton: Princeton University Press.

Grosse, R., \& J. Behrman. (1992). Theory in International Business. Transnational Corporations 1 (1), 93-126.

Grosse, R. (Ed.). (2005). International business and government relations in the 21st century. Cambridge: Cambridge University Press.

Haley, U. (2001). Multinational corporations in political environments. Singapore: World Scientific.

Hobson, J. (1965). Imperialism: astudy. Ann Harbor: University of Michigan Press.

Hurrell, A. (2006). On global order. Oxford: Oxford University.

Hurrell, A. (2010). Brazil and the new global order. Current History, 109(724), 60.

Hurrell, A. (2011). The theory and practice of global governance: the worst of all possible worlds? International Studies Review, 13(1), 144-154.

Ibarra-Colado, E. (2006). Organization studies and epistemic coloniality in Latin America: thinking otherness from the margins. Organization, 13(4), 463-488. 
Ikenberry, G. (2008). Liberal order building.In M.Leffler, \& J.Legro(Eds.).To lead the world. Oxford: Oxford University.

Jack, G, Calás, M, Nkomo, S, \& Peltonen, T. (2008). Critique and international management: an uneasy relationship? Academy of Management Review, 33(4), 870-884.

Johanson, J, \& Vahlne, J. (1977). The internationalization process of the firm: a model of knowledge development and increasing foreign market commitments. Journal of International Business Studies, 8(1), 23-32.

Kunz, B. (1997). Marshall Plan commemorative section: the Marshall Plan reconsidered: a complex of motives. Foreign Affairs, 73(3), 162-170.

Leal, C. (2005). 0 investimento das empresas portuguesas no Brasil: uma experiência de diplomacia econômica? Dissertação (Mestrado em Gestão Pública). Universidade de Aveiro, Aveiro - Portugal.

Lee, D, \& Hudson, D. (2004). The old and new significance of political economy in diplomacy. Review of International Studies, 30(3), 343-360.

Martínez, Z, \& Toyne, B. (2000).What is international management, and what is its domain? Journal of International Management, 6(1), 11-28.

McCrew, A. (2008). Globalization and global politics. In J.Baylis, S. Smith, \& P. Owens (Orgs.). Theglobalization of world politics. Oxford: Oxford University.

Mignolo, W. (2011). The darker side of western modernity: global futures, decolonial options. London: Duke University Press.

Miller, C. (2007). Democratization, international knowledge institutions, and global governance. Governance, 20(2), 325-357.

Murphy, J, \& Zhu, J. (2012). Neo-colonialism in the academy? AngloAmerican domination in management journals. Organization, 19(6), 915-927.

Nye, J, Jr. (2010). The future of American power: dominance and decline in perspective. Foreign Affairs, 89(6), 2-12.

Parmar, I. (2002). American foundations and the development of international knowledge networks. Global Networks, 2(1), 13-30.

Porto-Gonçalves, C. W. (2008). Outra verdade inconveniente - a nova geografia política da energia numa perspectiva subalterna. Universitas Humanística. 66, 327-365.

Ramamurti, R. (2009). What have we learned about emerging market EMNEs? In R. Ramamurti, \& J. Singh (Eds.). Emerging multinationals in emerging market (pp. 399-426). Cambridge: Cambridge University Press.

Ramamurti, R. (2011). Impact of the crisis on new FDI players: past, present and future of sovereign wealth funds, private equity and emerging market transnational corporations. Transnational Corporations, 20(1), 39-68.
Rosa, A, \& Alves, M. (2011). Pode o conhecimento em gestão e organização falar português? RAE-Revista de Administração de Empresas, 51(3), 255-264.

Santos, B, Cohn, A, \& Camargo, A. (2001). Brasil-Portugal: entre o passado e o futuro - o diálogo dos 500 anos. Rio de Janeiro: EMC.

Saraiva, F. (2000). 500 anos de relações entre Brasil e Portugal. Revista Brasileira de Política Internacional, 43(1), 189-191.

Silva, J. R. (2002a). Portugal/Brasil: uma década de expansão das relações econômicas, 1992-2002. wwLisboa: Terramar.

Silva, J. R. (2002b). Estados e empresas na economia mundial. Lisboa: Vulgata.

Silva, J. R. (2005). A internacionalização das empresas portuguesas: aexperiência brasileira. RAE-Revista de Administração de Empresas, 45, 102-115.

Silva, J. R. (2006). O investimento directo estrangeiro. In A. Romão (Ed.). A economia portuguesa 20 anos após a adesão. Coimbra: Edições Almedina.

Silva, J. R. (2012). Laços económicos com o Brasil:um imperativo estratégico para Portugal. Revista Portuguesa e Brasileira de Gestão, 11(2-3), 2-20.

Simões, V, \& Cartaxo, R. (2011). Inward FDI in Portugal and its policy context, 2011.Vale Columbia Center on Sustainable International Investment, Columbia FDI profiles, June 27, 1-27. Recuperado em 19 janeiro, 2015 de http://academiccommons.columbia.edu/catalog/ ac\%3A135223.

Stake, R. (2005).Qualitative case studies.In N.Denzin, \&Y. Lincoln (Orgs.). The Sage Handbook of qualitative research (3a ed, pp. 443-466) Thousand Oaks, CA: SAGE.

Steger, M. (2009).Globalisms. New York: Rowman\& Littlefield.

Stopford, J. (2005). Revisiting rival states. In R. Grosse (Ed.). International business and government relations in the 21st century. Cambridge: Cambridge University Press.

Stopford, J, \& Strange, S. (1991). Rival states and rival firms. Cambridge: Cambridge University Press.

Strange, S. (1994). States and markets (2aed.). London: Pinter Publishers.

United Nations Conference on Trade and Development.(2011). World Investment Report 2011. New York and Geneva: United Nations.

Wells, L. (2009). Foreword to the paperback edition. In A.Goldstein (Ed.). Multinational companies from emerging markets (2a ed, pp. 1012). Hampshire: Palgrave MacMillan.

Westwood, R, \& Jack, G. (2008).The US commercial-military-political complex and the emergence of international business and management studies. Critical Perspectives on International Business, 4(4), 367-388. 